Tarja Tamminen^, Atte Mikkelson, Matti Siika-aho, Kristiina Kruus, Jaakko Pere, Fernando José Borges Gomes and Jorge Luiz Colodette

\title{
Deposition of xylan isolated from Pennisetum purpureum on fibres of Eucalyptus globulus and characterisation of the composition of the surface xylans by immunolabelling and enzymatic peeling
}

https://doi.org/10.1515/hf-2018-0002

Received January 5, 2018; accepted May 25, 2018; previously published online July 19, 2018

\begin{abstract}
Adsorption of xylan on pulp is a potential method to improve its properties, especially refinability for high quality printing and writing (P\&W) paper grades. In this study, elephant grass [Pennisetum purpureum (Schumach.)] xylan was used for this purpose. The xylan was extracted using cold caustic extraction (CCE) from P. purpureum brown pulp, produced by the Soda-AQ process (kappa 20). Xylan resorption was accomplished during the oxygen delignification phase of eucalypt [Eucalyptus globulus (Labill.)] pulp to avoid problems induced by the colour of the lignin-contaminated deposited xylan. Immunolabelling and enzymatic peeling methodologies were compared for the analysis of the spatial distribution of xylan in the fibre wall. The labelling appeared unevenly as faint and brighter patches on fibre surfaces. Increased labelling of xylan was detected on the samples with precipitated $P$. purpureum xylan. The enzymatic peeling method using a total hydrolysis enzyme mixture yielded a composition gradient as a function of time, showing clear xylose (Xyl) enrichment in the very beginning of the reaction, reflecting hydrolysis of fibre surfaces. Pure xylanase and endoglucanase hydrolyses yielded different product patterns and kinetics compared to total hydrolysis, but interpretation of those results in terms of xylan localisation was not straightforward.
\end{abstract}

\footnotetext{
*Corresponding author: Tarja Tamminen, VTT Technical Research Centre of Finland, VTT, Espoo, P.O. Box 1000, FI-02044 VTT, Finland, e-mail: tarja.tamminen@vtt.fi

Atte Mikkelson, Matti Siika-aho, Kristiina Kruus and Jaakko Pere: VTT Technical Research Centre of Finland, VTT, Espoo, FI-02044 VTT, Finland

Fernando José Borges Gomes: Department of Forest Products, Federal Rural University of Rio de Janeiro, 23890-000, Rio de Janeiro, Seropédica - RJ, Brazil

Jorge Luiz Colodette: Laboratório de Celulose e Papel, Departamento de Engenharia Florestal, Universidade Federal de Viçosa, 36.570-000 - Viçosa, MG, Brasil
}

Keywords: elephant grass, enzymatic hydrolysis, Eucalyptus globulus, fibre surface composition, immunolabelling, Pennisetum purpureum, xylan

\section{Introduction}

Xylan in pulp is very important for the production of printing and writing $(\mathrm{P} \& \mathrm{~W})$ paper grades because it facilitates pulp refining and increases fibre bonding. It is therefore interesting to increase the pulp xylan content. Some grasses are rich in xylan, but they are not suitable raw materials for paper applications due to their fibre morphology. Thus, xylans extracted from grasses could potentially be incorporated, e.g. onto eucalypt fibres in order to improve pulp quality through better fibre-fibre bonding (Dahlman et al. 2003; Danielsson and Lindström 2005; Köhnke and Gatenholm 2007) and also to increase the overall fibre line yield (Aurell 1965; Muguet et al. 2011). Resorption of xylan on eucalypt fibres during the oxygen delignification step is addressed in the present paper as a novel approach, based on elephant grass [Pennisetum purpureum (Schumach.)] as the xylan source.

High-quality P\&W paper grades require pulps of high tensile strength (TS) because they are manufactured in high-speed machines (Muguet et al. 2011). Eucalypt fibres are well suited and produced for $\mathrm{P} \& \mathrm{~W}$ paper grades, which require significant mechanical refining (beating) to reach high TS and benefit largely from a high xylan content pulp for energy savings. On the other hand, tissue paper grade pulps are only slightly refined but still benefit from xylanrich pulps due to their naturally high unbeaten TS.

Pulps containing high levels of xylans have a tendency to high bonding strength (BS), particularly TS, and are less prone to hornification (Köhnke and Gatenholm 2007), and these traits are quite relevant for eucalyptus fibres aimed at replacing softwood fibres for P\&W grade applications. One possible mechanism of how xylan deposited on kraft pulp fibres increases TS and BS is due to introduction of new carboxylic groups into fibres bound to xylan (Sihtola and Blomberg 1975; Schonberg et al. 2001; Sjöberg et al. 
2002). Fibres with higher acid group content swell more, exposing larger surface areas with potentially more reactive sites available for interaction (Eriksson and Sjöström 1968). In addition, the increased flexibility and conformability increases fibre bonding.

The hemicelluloses are present in the whole fibre wall, both on the surface and in the innermost layers (Mobarak et al. 1973; Bachner et al. 1993; Schonberg et al. 2001). Both for hardwood and softwood pulps, the concentration of hemicelluloses, their number-average molar mass (Mn), and weight-average molar mass (Mw) are higher in the fibre surface layers (Dahlman et al. 2003). Thus, these parameters may serve as sensitive indicators for predicting the potential surface properties and bonding ability of pulp fibres. Hemicelluloses may act as an effective stress-transfer matrix (Kersavage 1973; Liitiä et al. 2005). Xylan sorption is enhanced at lower $\mathrm{pH}$ values within the alkaline range (Aurell 1965; Danielsson and Lindström 2005; Danielsson 2007) and there is evidence that higher temperatures increase xylan sorption onto cotton fibres (Yllner and Enström 1956; Danielsson and Lindström 2005). It has also been shown that the xylan resorption process is strongly affected by the amount of xylan present in the sorption liquor (Yllner and Enström 1956; Hansson and Hartler 1969; Muguet et al. 2011) as well as their structure (Yllner and Enström 1956; Hansson and Hartler 1969; Westbye et al. 2006). Sorption liquors having high xylan concentration tend to enhance sorption (Muguet et al. 2011) and a low number of substituents on the xylan chain will also facilitate the sorption (Yllner and Enström 1956; Axelsson et al. 1962; Hartler and Lund 1962; Hansson and Hartler 1969; Westbye et al. 2006).

Due to the variety of possible mechanisms how hemicelluloses may contribute to the pulp strength characteristics, it is crucial to know whether they are situated on the inner or outer fibre surfaces or deeper inside the fibre wall matrix. As mentioned earlier, the surface layers contain more xylan than the bulk fibres as found using enzymatic peeling with enzyme mixtures. Monitoring the level of hydrolysis and hydrolysate composition led to the conclusion that fibre surfaces are hydrolysed fastest of the leading xylan degradation products. Specific hemicellulases have also been applied for fibre surface analysis, combined with electron spectroscopy for chemical analysis (ESCA) analysis of the liberated fibre surface (Buchert et al. 1996) in order to reveal the dissolution and reprecipitation behaviour of xylan in kraft pulping. One significant finding was that xylan dissolution is accompanied by dissolution of lignin in the form of lignin-carbohydrate complexes (LCCs), which consequently leads to reprecipitation of lignin together with xylan. Use of specific enzymes as an analytical tool for fibre surface characterisation is revisited in the present study, now following the hydrolysis degree as a function of time similar to what is done in the total hydrolysis. In addition, the lignin components in alkaliextracted xylans will be analysed in terms of content, molar mass distribution (MMD) of the LCCs. The evaluation of the relevance of the undesired co-precipitation of lignin together with xylan will be in focus. A method based on antibodies combined with confocal microscope detection of the fibres will be applied for chemical mapping (Lappalainen et al. 2004). The expectation was that the xylan distribution on the surface can be detected visually. The xylan in focus was isolated using cold caustic extraction (CCE) from P. purpureum grass pulp and deposited on eucalyptus pulp during the oxygen delignification stage.

\section{Materials and methods}

Extraction of $P$. purpureum xylan and its redeposition on eucalyptus pulp: Xylans were extracted from an unbleached paper grade SodaAQ pulp from P. purpureum (kappa number, KN 20, 18.5\% xylan) using CCE at 10\% consistency, $60 \mathrm{~min}$ and room temperature. White liquor (active alkali of $150 \mathrm{~g} \mathrm{l}^{-1}$ and sulfidity of $23 \%$ ) with two alkali concentrations were used, namely: 400 and $700 \mathrm{~kg} \mathrm{NaOH}$ (Merck S/A, São Paulo, SP, Brazil) per odt pulp, which corresponds to 44.4 and $77.8 \mathrm{~g} \mathrm{l}^{-1}$ $\mathrm{NaOH}$ concentration, respectively. At the end of reaction, the CCE liquor was removed from the slurry by centrifugation. The xylan concentrations in the two CCE filtrates were 11.1 and $14.4 \mathrm{~g} \mathrm{l}^{-1}$. These filtrates were neutralised to $\mathrm{pH} 10.5$ with sulfuric acid (Merck S/A, São Paulo, $\mathrm{SP}$, Brazil) and stored under refrigeration for further evaluation.

The two CCE liquors were the source of xylan to be redeposited onto an unbleached Eucalyptus globulus (Labill.) soda-AQ pulp (KN 15 , xylan content of $16.5 \%)$. The xylan reabsorption was carried out in the oxygen delignification stage, which was run in a Mark V mixer/ reactor (Quantum Technologies Inc., Akron, OH, USA). The E. globulus brown pulp sample was deposited at 35\% consistency into the hastelloy reactor bowl and sufficient CCE filtrate plus $\mathrm{NaOH}$ solution (250 $\mathrm{g} \mathrm{l}^{-1}$ ) were added until the consistency reached $12 \%$. The same volumes of the two CCE filtrates (11.1 and $14.4 \mathrm{~g} \mathrm{l}^{-1}$ xylans) were added to the reactor. The xylan charges to the 0 -stage were 5.5 and $7.2 \%$ (b.o. pulp), respectively, for the two CCE xylan extracts. The alkali charge in the $\mathrm{O}$-stage was maintained constant at $2 \%$ (b.o. pulp) in both case scenarios and was provided by the $250 \mathrm{~g} \mathrm{l}^{-1} \mathrm{NaOH}$ solution plus the alkali contained in the $\mathrm{pH} 10.5$ xylan extracts. The O-stage was run at $12 \%$ consistency, $100^{\circ} \mathrm{C}, 60 \mathrm{~min}, 600 \mathrm{kPa}$, with $1.6 \% \mathrm{O}_{2}$ charge b.o. pulp weight. At the end of the reaction, the pulp was washed extensively with excess water for $24 \mathrm{~h}$ in running water. The $\mathrm{O}$-stage gravimetric yield for the E. globulus pulp was calculated as 101.3 and $102.4 \%$, respectively, for the two xylan concentrations. The xylan contents of the two pulps after oxygen delignification were 19.7 and $20.7 \%$, respectively.

Extraction and characterisation of $P$. purpureum and eucalyptus xylans: For analytical purposes, xylans were extracted from the P. purpureum and eucalypt brown pulps (described above) using CCE 
at 10\% consistency, $15 \mathrm{~min}$ at room temperature with an alkali charge $550 \mathrm{~kg}$ of $\mathrm{NaOH}$ odt. The xylans were precipitated from the solutions by ethanol (Sigma Aldrich Brasil, Jurubatuba, SP, Brazil) addition and air-dried (Longue Júnior et al. 2013).

The compositions of the CCE-extracted and precipitated xylans were analysed. The samples were first washed with ion-exchanged water to remove the main part of the residual inorganics, followed by dialysis. Cellulose ester membranes Spectra/POR ${ }^{\circledR}$ Biotech with cut-off 100-500 Da (Spectrum Laboratories Inc., Rancho Dominguez, CA, USA) were used. The carbohydrate compositions were determined using acid methanolysis as described by Willför et al. (2009). The fibres were also submitted to enzymatic hydrolysis as described below. The end point ( $48 \mathrm{~h}$ ) was analysed for total composition, including oligomeric structures to detect the hexenuronic acid (HexUA) containing structures. The concentrations of monosaccharides - arabinose (Ara), rhamnose (Rha), galactose (Gal), glucose (Glc), xylose (Xyl) and mannose (Man) - and oligosaccharides were analysed using highperformance anion exchange chromatography (HPAEC) (Dionex ICS3000) combined with pulse amperometric detection (PAD) (Dionex Corporation, Sunnyvale, CA, USA). Pre- and separation columns (Dionex CarboPac PA-1) were employed as described in the literature (Tenkanen et al. 1997; Tenkanen and Siika-Aho 2000; Willför et al. 2009). The standard deviations (SD) for the individual sugar amounts were Ara 1.2-3.3\%, Gal 0.5-1.3\%, Glc 0-1.2\%, Xyl 0.3-3.9\% and Man $1-2.1 \%$. These SDs are in line with earlier published results by Willför et al. (2009) and Dahlman et al. (2000).

For MMD, the xylan samples were dissolved in alkali (4 mg sample into $4 \mathrm{ml}$ of $1 \mathrm{M} \mathrm{NaOH}$ ) overnight under magnetic stirring at room temperature. The preparations were filtered with $0.45 \mu \mathrm{m}$ syringe filter and analysed using a high performance size exclusion chromatography (HPSEC) system (Waters, Milford, MA, USA) consisting of an isocratic pump (Waters 510), Waters 717 plus Autosampler with a $100 \mu$ l loop, PSS MCX 1000 and 100000 columns (100-70 000 and 1000-1000 $000 \mathrm{Da}$ ), differential refractive index (RI) detector (Waters 410) and Waters 2998 Photodiode Array Detector. The columns were kept at $25^{\circ} \mathrm{C}$ and the flow rate of the mobile phase $(0.1 \mathrm{M}$ $\mathrm{NaOH}$ ) was fixed at $0.5 \mathrm{ml} \mathrm{min}^{-1}$. Calibration was done with Pullulan and polystyrene sulfonate (PSS) standards (Hakala et al. 2013).

Fibre surface analysis by immunolabelling: Immunolabelling microscopy served for surface mapping of precipitated P. purpureum xylan on the eucalypt pulp fibres according to Lappalainen et al. (2004). A primary antibody was used (produced in-house), which recognises an epitope consisting of a short xylooligosaccharidic stretch carrying a 4-0-methyl-glucuronic acid residue (MeGlcA-Xyl2-3), but also polymeric xylan without cross-reactivity with other surface polymers like glucomannan. Therefore, this primary antibody is assumed to be active towards both the grass and E. globulus xylans.

Fibre surface analysis by enzymatic hydrolysis: Two hundred milligram samples were hydrolysed using three enzyme systems: (1) combination of commercial cellulase (Econase, $\mathrm{AB}$ Enzymes, Rajamäki, Finland), xylanase (Ecopulp X-200, AB Enzymes, Rajamäki, Finland), mannanase (Gamanase, Novozymes, Bagsvaerd, Denmark) and $\beta$-glucosidase (Novozyme 188, Novozymes, Bagsvaerd, Denmark). The mixture was charged according to endoglucanase dosage of $50 \mathrm{FPU} \mathrm{g}{ }^{-1}$ at $1.6 \%$ consistency for a maximum $48 \mathrm{~h}$ at $40^{\circ} \mathrm{C}$ and pH 5 (Tenkanen et al. 1999). (2) Endoglucanase I (Cel7B) was purified from Trichoderma reesei culture filtrate according to Suurnäkki et al. (2000). Enzyme dosage of $0.25 \mathrm{mg}$ protein $\mathrm{g}^{-1}$ of dry pulp, $1.6 \%$ consistency, $45^{\circ} \mathrm{C}$ and $\mathrm{pH}$. This enzyme has a high activity towards both xylan and cellulose. (3) Xylanase treatments were performed using xylanase purified from $T$. reesei culture filtrate according to (Tenkanen et al. 1992) but omitting the last gel filtration step. Xylanase dosage of 500 nkat g-1 was applied at $1.6 \%$ consistency, $45^{\circ} \mathrm{C}$ and $\mathrm{pH}$ 5. Samples were taken during the hydrolyses at several time points and boiled for $10 \mathrm{~min}$ to inactivate the enzymes. Samples from each time point were also hydrolysed further by means of the total enzyme hydrolysis procedure to deliver the total composition as monosaccharides and analysed using HPAEC-PAD according to Willför et al. (2009) as described above for the extracted xylans.

\section{Results and discussion}

\section{Characterisation of the $P$. purpureum and eucalyptus xylans}

The compositions of the isolated xylans were analysed, while the original xylan samples were purified prior to the analysis as described in the experimental, because the residual alkali in the samples interfered with the composition analysis. Methanolysis is the preferred method for uronic acids for non-cellulosic samples. One aim was to detect the compositional differences between the two xylans depending on their origin. As seen in Table 1, the P. purpureum xylan is highly substituted by Ara side groups (ara:xyl=1:15), while only traces of Ara were detected in eucalyptus xylan (ara:xyl=1:800). Thus, the presence of Ara in the eucalyptus pulps is an indicator for deposited P. purpureum xylan.

Table 1: Carbohydrate composition of the isolated xylans based on methanolysis.

\begin{tabular}{lrrrrr}
\hline \multirow{2}{*}{ Sugars } & \multicolumn{2}{c}{ Xylan of $P$. purpureum } & & \multicolumn{2}{c}{ Xylan of $E$. globulus } \\
\cline { 2 - 3 } & \multicolumn{1}{c}{$(\%)^{\mathrm{a}}$} & $(\%)^{\mathrm{b}}$ & & $(\%)^{\mathrm{a}}$ & $(\%)^{\mathrm{b}}$ \\
\hline Ara & 5.1 & 6.2 & 0.1 & 0.1 \\
Rha & 0.2 & 0.2 & 0.1 & 0.1 \\
Xyl & 74.2 & 89.9 & 71.2 & 98.3 \\
Man & 0.3 & 0.3 & 0.1 & 0.1 \\
Gal & 0.4 & 0.4 & 0.5 & 0.6 \\
Glc & 1.9 & 2.3 & 0.3 & 0.4 \\
GalA & 0.1 & 0.1 & 0.1 & 0.1 \\
MeGlcA & 0.2 & 0.2 & 0.1 & 0.1 \\
GlcA & 0.3 & 0.3 & 0.1 & 0.1 \\
Total & 82.5 & 100.0 & 72.5 & 100.0 \\
\hline
\end{tabular}

aShare of anhydrosugars of the total polysaccharides (sum of anhydrosugars). Anhydrosugars were calculated from the monosaccharides using correction factor 0.88 for pentoses, 0.90 for hexoses, 0.91 for GlcA and GalA and 0.92 for MeGlcA.

${ }^{b}$ Share of anhydrosugars normalised to $100 \%$. 


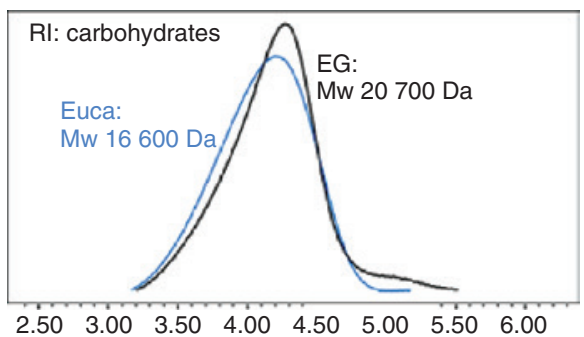

$2.50 \quad 3.00 \quad 3.50 \quad 4.00 \quad 4.50 \quad 5.00 \quad 5.50 \quad 6.00$

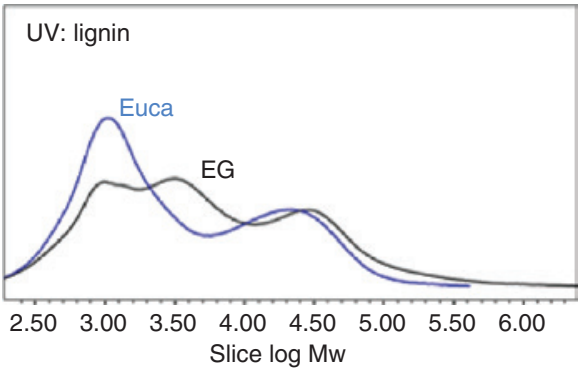

Figure 1: Molar mass distribution of the Pennisetum purpureum (Schumach.) and eucalypt xylans detected using RI detector for the carbohydrates and UV $280 \mathrm{~nm}$ for the lignin impurity.

The HexUA-contents of the xylan samples were found to be 0.45 and $4.75 \mathrm{mg}$ per $100 \mathrm{mg}$ (corresponding to 25 and $270 \mathrm{mmol} \mathrm{kg}^{-1}$ ) for the P. purpureum and eucalyptus samples, respectively. Thus, deposition of $P$. purpureumbased xylan should not significantly increase the HexUA content of the pulp.

As inorganic contaminants were removed by dialysis, the impurity of xylans is of lignin origin. The lignin content in the $P$. purpureum sample was lower than in the eucalypt sample. The presence of lignin was verified with MMD using ultraviolet (UV) $(280 \mathrm{~nm}$, lignin detection) and RI (carbohydrate detection) (Hakala et al. 2013). The average Mw of the P. purpureum and eucalypt xylans was 20700 and $16600 \mathrm{Da}$, respectively. In both cases, the lignin moiety was similar, which was probably bound to the xylan (Figure 1). The average Mw of the lignin contaminant in the P. purpureum and eucalypt xylans were 23400 and $11200 \mathrm{Da}$, respectively. However, linkages between xylan and lignin are expected to increase artificially this average data. The MMD of unpurified xylan samples was also recorded. After the purification, the solubility of the samples in alkali was insufficient and thus the analysis was not reliable because of aggregation effects. This confirms the earlier finding (Buchert et al. 1996) that alkali extracted xylans are in reality LCCs, and reprecipitation of xylan also leads to lignin content increment on fibre surfaces.

\section{Deposition of $P$. purpureum xylan on eucalyptus pulp}

The P. purpureum xylan was redeposited onto eucalyptus brown pulp (KN 20) during the oxygen delignification stage. The carbohydrate compositions of the pulps were determined using total enzymatic hydrolysis ( $48 \mathrm{~h}$ ). The enrichment of the xylan-deposited pulps is clearly seen in Table 2. The ara:xyl ratio was also lowered by increasing xylan deposition due to the observed higher degree of Ara
Table 2: Carbohydrate composition of the pulps.

\begin{tabular}{lrrrrrr}
\hline Pulp & Ara (\%) & Gal (\%) & Glc (\%) & Xyl (\%) & Man (\%) & Ara/Xyl \\
\hline Reference & 0.8 & 1.2 & 79.3 & 16.1 & 2.6 & $1: 20$ \\
CCE 400 & 1.2 & 1.1 & 75.1 & 19.9 & 2.7 & $1: 17$ \\
CCE 700 & 1.5 & 1.4 & 71.7 & 22.2 & 3.2 & $1: 15$ \\
\hline
\end{tabular}

substitution in the $P$. purpureum xylan. However, the ratio was significantly lower in the eucalypt pulp (1:20) compared to the extracted eucalypt xylan (1:800), probably due to cleavage of Ara side chains during the extractions. This means that the extracted xylan cannot be regarded as a good model for eucalyptus pulp xylan. Consequently, only the distribution of Xyl rather than Ara is a reliable indicator of xylan deposition.

\section{Fibre surface composition by immunolabelling}

Immunolabelling microscopy served for surface mapping of xylan deposition. The large antibodies do not penetrate into the fibre, thus they are surface specific. The antibody applied here is able to recognise the xylan both from eucalyptus and P. purpureum. Images of the labelled samples are presented in Figure 2. In general, the antibody labelling of xylan was successful. However, as already pointed out, the method does not discriminate between the native and reprecipitated xylan. On the untreated reference, moderate labelling is visible, which appears uneven and faint with some brighter patches on fibre surfaces. Extensive labelling was observed especially on damaged fibres and fibrillated fines. This is probably due to increased accessibility of xylan at fibre kinks and dislocations. The high surface area of fines also enhances recognition by the rather large immunoglobulin molecules. In addition, fines contain higher xylan concentrations than fibres. No significant difference was seen between the two xylan 

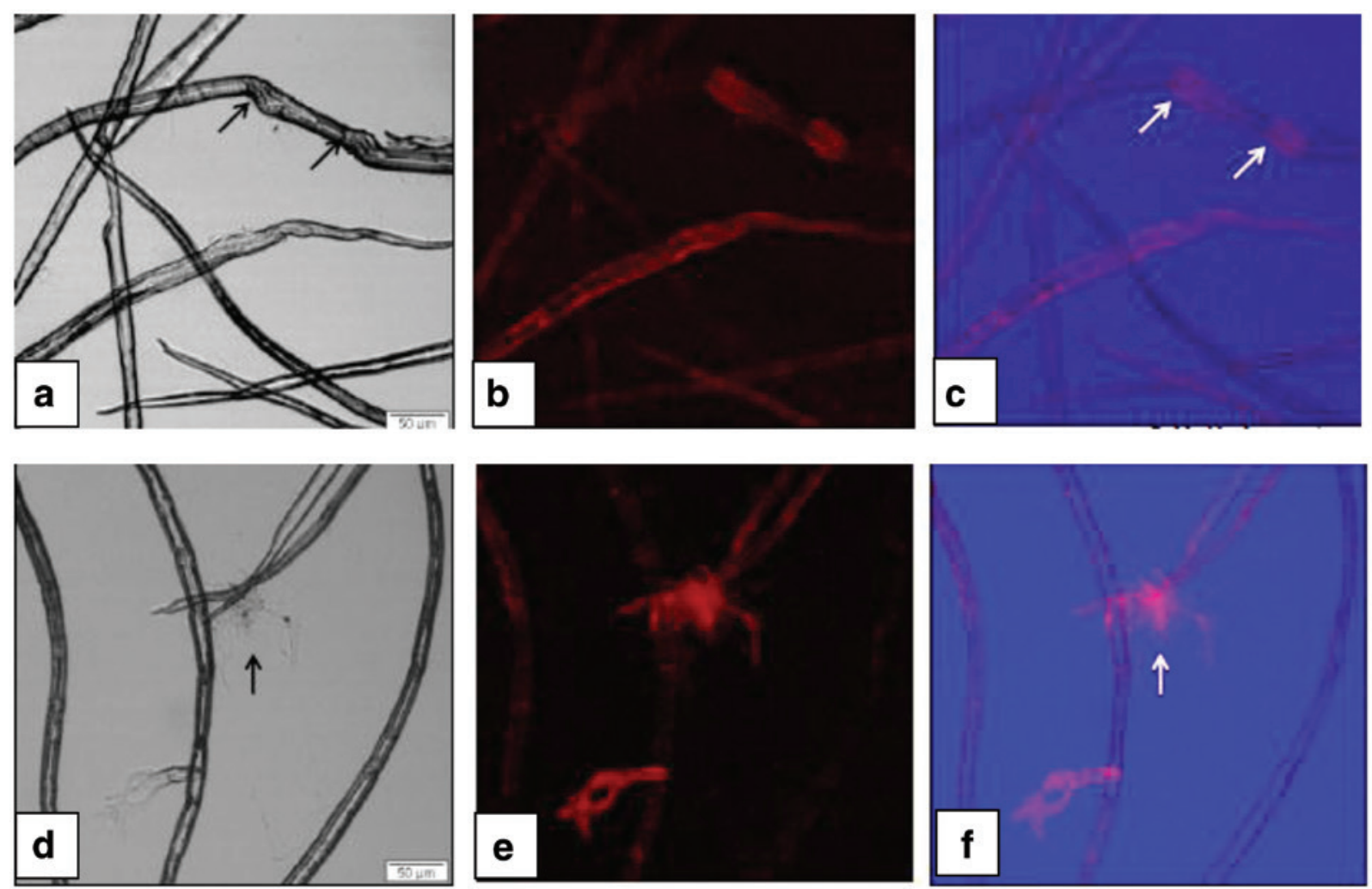

Figure 2: Immunolabelling of xylan on eucalypt fibres.

a-c: reference sample, d-f: CCE400 with precipitated xylan. (a) and (d): bright-field images, (b) and (e): images of fluorescence emitted by the Alexa Fluor 633 labelled immunoconjugate, (c) and (f): syntheses of the two images. The arrows indicate typical sites of xylan enrichment in the two cases.

deposited samples (only one of them is presented in Figure 2). Accordingly, the xylan coverage of the fibres is not even, and the labelling is partly due to the xylan-enriched outer fibre layers and partly from the unevenly distributed fineslike patches. These images are consistent with those of the previous immunochemical studies concerning the agglomeration of added xylan on wood chips and cellulose fibres (Salmen et al. 2013; Hutterer et al. 2017).

\section{Fibre surface composition by enzymatic hydrolysis}

Enzymatic peeling methods were applied according to Sjöberg et al. (2005) for the total enzymatic hydrolysis. In this method, eight time points $(1,5,15$ and $30 \mathrm{~min}$, and 1 , 2, 24 and $48 \mathrm{~h}$ ) were selected for monitoring the hydrolysis process. In this time period, practically quantitative hydrolysis was reached. The idea behind this method is that fibre surfaces hydrolyse prior to the inner parts. The surface composition is represented by the first hydrolysis fractions, while the final hydrolysis results are typical for the overall composition. As expected, the proportion of xylan was highest in all samples in the beginning of the hydrolysis (Figure 3a), and also highest in the xylanenriched samples. The slight enrichment detected in the reference samples was probably due to native enrichment of xylan in the surface layers. The point, at which $10 \%$ of the material is hydrolysed, can be interpreted as the approximated surface xylan content. Figure $3 \mathrm{~b}$ shows the xylan contents at 10 and $90 \%$ hydrolysis levels, which are for the surface and bulk compositions, respectively. The results indicate that the xylan enrichment in the CCE 400 and CCE 700 pulps is significantly higher on the fibre surfaces compared to the average composition. Therefore, the added xylan is expected to improve significantly the paper's technical properties.

The samples were also hydrolysed by pure $T$. reesei endoglucanase I (Cel7B) (Figure 4). This enzyme has a high activity on both xylan and cellulose (Suurnäkki et al. 2000). The hydrolysates consisted mainly of Xyl, but the degree of hydrolysis remained low perhaps due to restricted enzyme penetration because of the lack of assisting enzymes (cellobiohydrolases and enzymes with side chain cleaving activities) that are needed for the complete hydrolysis of the cell wall polysaccharides. Thus, the 

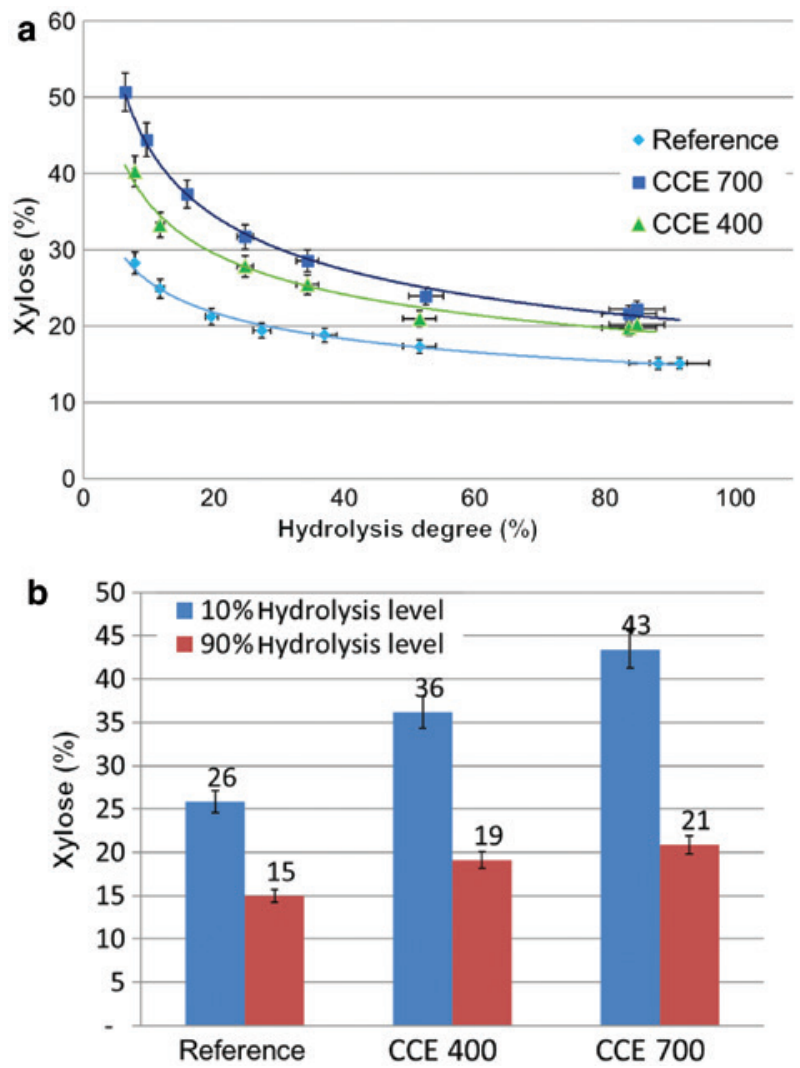

Figure 3: Treatment by the total enzymatic hydrolysis mixture. (a) Xylan content (as xylose proportion in the hydrolysate) of the fibre surface $(10 \%$ hydrolysis level) and bulk composition ( $90 \%$ hydrolysis level) by enzymatic peeling in the CCE 400, CCE 700 and reference pulps. (b) Xylose proportion of fibre surface and bulk material in the $10 \%$ and $90 \%$ hydrolysis levels from the same experiment.

result probably represents the outermost surface composition. The actual level of xylan enrichment is probably lower than observed, as xylan is the preferable substrate for the endoglucanase I. The $2 \%$ and $14 \%$ hydrolysis levels were selected as the early and final stages of the hydrolysis. The pulps could be clearly differentiated according to their treatment history. However, the absolute values of the xylan hydrolysis levels are arbitrary due to the restricted hydrolysis capacity of the enzyme.

Hydrolysis by pure specific xylanase liberated in practice only xylan. This is the reason why the intermediate hydrolysis points did not reveal any additional information compared to the final hydrolysis time points of $24 \mathrm{~h}$ and $48 \mathrm{~h}$, without yield increments between these points. The final levels of xylan hydrolysis were 3.0\% (reference), 5.8\% (CCE 400) and 6.8\% (CCE 700). In line with the sample treatment, highest xylan levels were found for the xylan deposited samples and lowest for the reference. However, the xylan enrichment on the fibre surface could not be clearly visualised by means of this method.
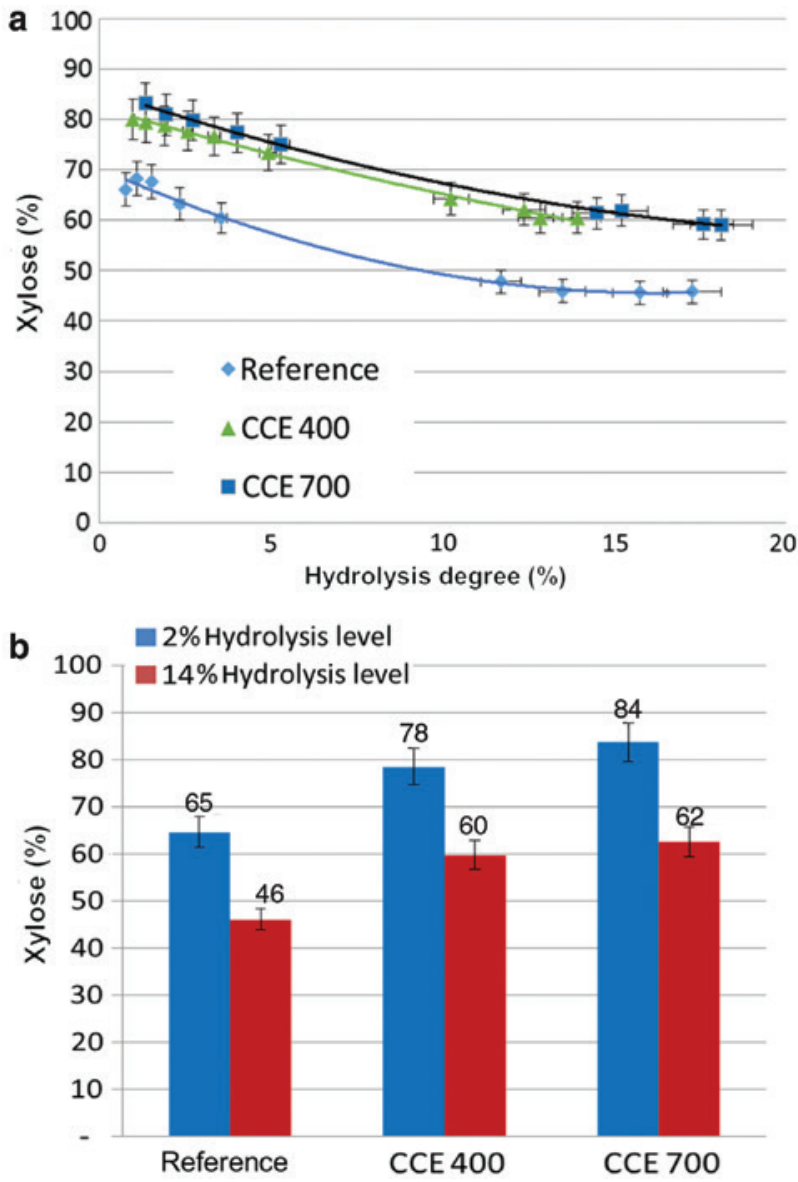

Figure 4: Treatment by endoglucanase I (Cel7B).

(a) Xylan content (as xylose proportion in the hydrolysate) of the fibre surface by enzymatic peeling in the CCE 400, CCE 700 and reference pulps as a function of hydrolysis level. (b) Xylose proportion of fibre surface and bulk material in the $2 \%$ and $14 \%$ hydrolysis levels from the same experiment.

\section{Conclusions}

Xylan was extracted from $P$. purpureum brown pulp by the CCE method and deposited on E. globulus pulp during the oxygen delignification stage. The isolated xylan had a high degree of substitution by Ara and low degree of substitution by HexUA. It was also contaminated by some lignin. Immunolabelling revealed that part of the E. globulus xylan in the reference sample is detectable by the method mainly at sites of fibre defects. In the xylandeposited samples, the xylan was detected in the form of separate patches attached to the surfaces. Total enzymatic hydrolysis, as a function of time, was an effective tool for surface composition analysis. Hydrolysate composition at $10 \%$ hydrolysis level was suggested to represent the fibre surface composition, while $90 \%$ hydrolysis level is indicative of the bulk composition. The enrichment of surface 
xylan was clear for the xylan-deposited samples, but also the native xylan enrichment in the reference sample was observed. Pure xylanase hydrolysis provided information about the total amount of xylan that is accessible to the enzyme without additional cell wall disruption. However, other factors than surface enrichment affected the result and reduced the applicability of this method for xylan localisation. Pure T. reesei endoglucanase I (Cel7B) leads to higher hydrolysis yields by releasing also some Glc from cellulose. Neither the results of this approach could be interpreted unambiguously in terms of xylan localisation. Stepwise peeling via total enzymatic hydrolysis combined with visual observation by immunolabelling are the methods of choice for monitoring the xylan coverage of pulp fibres.

Acknowledgements: The research leading to these results has received funding from the European Community's Seventh Framework Programme FP7/2007-2013, FP7 Food, Agriculture and Fisheries, Biotechnology, Funder Id: 10.13039/100011262, under grant agreement no KBBE2009-3-244362 LignoDeco (EU/Brazil co-operation project).

Author contributions: All the authors have accepted responsibility for the entire content of this submitted manuscript and approved submission.

Employment or leadership: None declared.

Honorarium: None declared.

\section{References}

Aurell, R. (1965) Increasing kraft pulp yield by redeposition of hemicelluloses. Tappi 48:80-84.

Axelsson, S., Croon, I., Enström, B. (1962) Dissolution of hemicelluloses during sulphate pulping Part 1. Isolation of hemicelluloses from the cooking liquor at different stages of a birch soda cook. Svensk Papperstidn. 65:693-697.

Bachner, K., Fischer, K., Bäuker, E. (1993) Zusammenhang zwischen Aufbau der Zellwa"nde und Festigkeitseigenschaften bei Faserstoffen von konventionellen und neuen Aufschlussverfaren. Das Papier 47:30-40.

Buchert, J., Carlsson, G., Viikari, L., Ström, G. (1996) Surface characterisation of unbleached kraft pulps by enzymatic peeling and ESCA. Holzforschung 50:69-74.

Dahlman, O., Jacobs, A., Liljenberg, A., Olsson, A.I. (2000) Analysis of carbohydrates in wood and pulps employing enzymatic hydrolysis and subsequent capillary zone electrophoresis. J. Chromatogr. A. 891:157-174.

Dahlman, O., Sjöberg, J., Jansson, U., Larsson, P.O. (2003) Effects of surface hardwood xylan on the quality of softwood pulps. Nordic Pulp Pap. Res. J. 18:310-315.
Danielsson, S. (2007) Xylan Reactions in Kraft Cooking Process and Product Considerations. Doctoral Thesis Royal Institute of Technology School of Chemical Sciences and Engineering Department of Fiber and Polymer Technology Division of Wood Chemistry and Pulp Technology, Stockholm 2007. TRITA-CHEReport 2007:78, ISSN 1654-1081, ISBN 978-91-7178-819-1, 73p. Danielsson, S., Lindström, M.E. (2005) Influence of birch xylan adsorption during kraft cooking on softwood pulp strength. Nordic Pulp Pap. Res. J. 20:436-441.

Eriksson, E., Sjöström, E. (1968) Influence of acidic groups on the physical properties of high-yield pulps. Tappi J. 51:56-59.

Hakala, T.K., Liitiä, T., Suurnäkki, A. (2013) Enzyme-aided alkaline extraction of oligosaccharides and polymeric xylan from hardwood kraft pulp. Carbohydr. Polym. 93:102-108.

Hansson, J., Hartler, N. (1969) Sorption of hemicelluloses on cellulose fibers. Part 1. Sorption of xylans. Svensk Papperstidn. 72:521-530.

Hartler, N., Lund, A. (1962) Sorption of xylans on cotton. Svensk Papperstidn. 65:951-955.

Hutterer, C., Fackler, K., Schild, G., Ibl, V., Potthast, A. (2017) Xylan localization on pulp and viscose fiber surfaces. BioResources 12:5632-5648.

Kersavage, P. (1973) Moisture content effect on tensile properties of individual Douglas-fir latewood tracheids. Wood Fiber Sci. 5:105-117.

Köhnke, T., Gatenholm, P. (2007) The effect of controlled glucuronoxylan adsorption on drying-induced strength loss of bleached softwood pulp. Nordic Pulp Pap. Res. J. 22:508-515.

Lappalainen, A., Tenkanen, M., Pere, J. (2004) Specific antibodies for immunochemical detection of wood-derived hemicelluloses. In: Hemicelluloses: Science and Technology. ACS Symposium Series Vol. 864. Eds. Gatenholm, P., Tenkanen, M. ACS, Washington, DC, pp. 140-156.

Liitiä, T., Hortling, B., Honkonen, P., Sneck, A., Joutsimo, O., Tamminen, T. (2005) Fibre morphology responsible for restricted solubility of softwood kraft pulp in LiCl/DMAC. In: International Symposium on Wood, Fibre and Pulping Chemistry, Auckland, New Zealand, 3:371-375.

Longue Júnior, D., Ayoub, A., Venditti, R.A., Jameel, H., Colodette, J.L., Chang, H.-M. (2013) Ethanol precipitation of heteropolysaccharide material from hardwood by alkaline extraction prior to the kraft cooking process. Bioresources 8:5319-5332.

Mobarak, F., El-Ashawy, A.E., Fahmy, Y. (1973) Hemicelluloses as additives in papermaking. 2 . The role of added hemicelluloses and hemicellulose in situ on paper properties. Cell. Chem. Technol. 7:325-335.

Muguet, M., Pedrazzi, C., Colodette, J.L. (2011) Xylan deposition onto eucalypt pulp fibers during oxygen delignification. Holzforschung 65:605-612.

Salmen, L., Filonova, L., Olsson A.-M., Hafrén, J., Daniel, G. Chemical Pulping. Localization of xylan (native and added) during pulping. Intern rapport nr 11 . Centre for Research on Ultrastructure of Wood Fibres, Uppsala, 2013.

Schonberg, C., Oksanen, T., Suurnäkki, A., Kettunen, H., Buchert, J. (2001) The importance of xylan for the strength properties of spruce kraft fibres. Holzforschung 55:639-644.

Sihtola, H., Blomberg, L. (1975) Hemicelluloses precipitated from steeping liquor in the viscose process as additives in papermaking. Cellul. Chem. Technol. 9:555-560. 
Sjöberg, J., Kleen, M., Dahlman, O., Agnemo, R., Sundvall, H. (2002) Analysis of carbohydrate and lignin in the surface and inner layers of softwood pulp fibres obtained employing various alkaline cooking process. Nord. Pulp Pap. Res. J. 17:295-301.

Sjöberg, J., Potthast, A., Rosenau, T., Kosma, P., Sixta, H. (2005) Cross-sectional analysis of the polysaccharide composition in cellulosic fibre materials by enzymatic peeling/high-performance capillary zone electrophoresis. Biomacromolecules 6:3146-3151.

Suurnäkki, A., Tenkanen, M., Siika-aho, M., Niku-Paavola, M.-L., Viikari, L., Buchert, J. (2000) Trichoderma reesei cellulases and their core domains in the hydrolysis and modification of chemical pulp. Cellulose 7:189-209.

Tenkanen, M., Siika-Aho, M. (2000) An $\alpha$-glucuronidase of Schizophyllum commune acting on polymeric xylan. J. Biotechnol. 78:149-161.

Tenkanen, M., Puls, J., Poutanen, K. (1992) Two major xylanases of Trichoderma reesei. Enzyme Microb. Technol. 14:566-574.
Tenkanen, M., Makkonen, M., Perttula, M., Viikari, L., Teleman, A. (1997) Action of Trichoderma reesei mannanase on galactoglucomannan in pine kraft pulp. J. Biotechnol. 55:191-204.

Tenkanen, M., Gellerstedt, G., Vuorinen, T., Teleman, A., Perttula, M., Li, J., Buchert, J. (1999) Determination of hexenuronic acid in softwood kraft pulps by three different methods. J. Pulp Paper Sci. 25:306-311.

Westbye, P., Svanberg, C., Gatenholm, P. (2006) The effect of molecular composition of xylan extracted from birch on its assembly onto bleached softwood kraft pulp. Holzforschung 60:143-148.

Willför, S., Pranovich, A., Tamminen, T., Puls, J., Laine, C., Suurnäkki, A., Saake, B., Uotila, K., Simolin, H., Hemming, J., Holmbom, B. (2009) Carbohydrate analysis of plant materials with uronic acid-containing polysaccharides A comparison between different hydrolysis and subsequent chromatographic analytical techniques. Ind. Crops Prod. 29:571-580.

Yllner, S., Enström, B. (1956) Studies of the adsorption of xylan on cellulose fibres during the sulphate cook. Part 1. Svensk Papperstidn. 59:229-232. 